\title{
RELATIONSHIP BETWEEN ADMINISTRATION OF STATINS AND BLOOD SERUM LEVELS OF SELECTED BIOCHEMICAL PARAMETERS
}

\author{
TATIANA ĎURČEKOVÁ ${ }^{1}$, JÁN MOCÁK ${ }^{1}$, JÁN BALLA ${ }^{2}$, \\ GABRIELA GROMANOVÁ ${ }^{2}$, KATARÍNA BORONOVÁ ${ }^{1}$ \\ ${ }^{1}$ Department of Chemistry, University of SS. Cyril and Methodius, J. Herdu 2, Trnava, \\ SK-917 01, Slovak Republic (tatiana.durcekova@ucm.sk) \\ ${ }^{2}$ Analytical-diagnostic laboratory, Kováčska 15, Prešov, SK-080 01, Slovak Republic \\ (jan.balla@mail.t-com.sk)
}

\begin{abstract}
Results of biochemical tests of 172 patient data (among them 84 men data and 88 women data, resp.) before and after administration of statins were studied. All monitored patients are characterized by lipoprotein metabolism failure or other kind of lipidaemia. The calculations were performed using several chemometrical methods pursuing visualization of most important biochemical parameters and classification of the patient blood samples by means of up-to-date software packages. The dependences of the content of most common biochemical parameters upon the treatment of patients by statins were elucidated in detail.
\end{abstract}

Key words: coronary artery diseases, statins, biochemical parameters, multivariate data analysis.

\section{Introduction}

Coronary heart disease remains the leading cause of mortality in the civilized countries. In medicine it is now an accepted principle that cholesterol lowering is of major importance in diminishing the risk of a developing coronary artery disease. Most patients with coronary artery disease require intensive drug therapy to achieve target lipid levels (KASTELEIN, 1999; SHIMOKATA et al., 2004).

The introduction of inhibitors of 3-hydroxy-3-methylglutaryl coenzyme A reductase (statins) in 1987 was a major advance in prevention and treatment of cardiovascular diseases. Several clinical trials have demonstrated the benefit of lipid lowering caused by statins for the primary and secondary prevention of coronary heart disease (LIAO, 2002; ISTVAN and DEISENHOFER, 2001).

The clinical practise of cardiovascular medicine has been innovated by the advent of the statins. The statins have a wide range of beneficial biologic effects in addition to lipid lowering, a phenomenon commonly termed a pleiotropic effect (FUJITA et al., 2008; GOUNARI et al., 2009). Statins act by inhibiting 3-hydroxy-3-methyl-glutaryl coenzyme A (HMG-CoA) reductase and thereby reducing cholesterol synthesis (GARCIA et al., 2008).

\section{Material and methods}

\subsection{Description of data}

Data from the out-patient department in Prešov were obtained in cooperation with the specialist internal (GROMANOVA, 2008). In this study, biochemical data steming 
from 172 probands were analyzed by several chemometrical methods in order to reveal relationships between administration of statins and the level of biochemical parameters. The investigated patients were characterized by lipoprotein metabolism failure and other kind of lipidaemia.

Two data tables (for men - 84 samples, and for women - 88 samples) containing the sample origin (patients) in rows and investigated variables in columns (10 biochemical parameters plus 1 combined parameter and age of the patient) were assembled. The following biochemical variables (often called as parameters) were selected: total cholesterol (tCHOL), high density lipoprotein cholesterol (HDLc), low density lipoprotein cholesterol (LDLc), triacylglycerols (TG), aterogenic index (AI) the combined parameter, creatinine (CREA), aspartate aminotransferase (AST), alanine aminotransferase (ALT), alkaline phosphatase (ALP), creatinine kinase (CK), and gamma-glutamyl transferase (GGT). The parameter values were measured before administration of statins and one year after the statin treatment. The patient samples objects were therefore divided into two groups: class 1 - parameter values before the treatment by statins and class 2 - parameter values one year after the treatment.

\subsection{Multidimensional data analysis}

The results of biochemical tests were subjected to multidimensional data analysis using four software packages. Statgraphics Plus 5.1 was utilized to perform cluster analysis (VANDEGINSTE et al., 1997) as well as principal component analysis (MASSART et al., 1997); SPSS 15 and SAS packages enabled to accomplish discriminant analysis and logistic regression (OTTO, 1999; SHARMA, 1996). Correlation analysis (MELOUN and MILITKY, 2002) was also made in addition to the mentioned more sophisticated statistical techniques using software JMP 6.0.

\section{Results and discussion}

\subsection{Correlation analysis}

Correlation analysis was performed in common for the patients' results obtained before and after the statins administration. It is represented by the correlation table containing the calculated pair (Pearson) correlation coefficients, which indicate the strength of correlation between all pairs of variables - biochemical parameters for men and women, distinctively. In order to see the measure of their importance, the correlation coefficient values were compared to the critical value of the sample correlation coefficient, $r=0.215$ for men dta set and 0.210 for women data set, which depends on the number of degrees of freedom (the sample number minus two) and the selected probability (usually 0.05 ). Consequently, all values in the correlation tables (Table 1, Table 2) indicating significant correlations are marked in bold. It can be seen from the observed values that many of the observed significant correlations (marked bold) are very well understandable, as e.g. between tCHOL a LDLc (strongest correlation for men and women), tCHOL and its component parts (LDLc and HDLc), 
tCHOL and TG (for men only), as well as the negative correlation between index of aterogenity AI and so called "good" cholesterol HDLc (high values of HDLc correspond to low values of AI). Similarly, significant correlations between the pairs AST - ALT and GMT - ALT are expectable. What is also interesting are the negative correlations for men between Age and any of the variables TG, and AI, which is pronounced after the statins intake. Strong positive correlations of TG with tCHOL and with AI as well as strong negative correlation of TG with HDLc, all observed only after the statins, may also be remarkable.

Table 1. Summary of correlation coefficients expressing mutual correlation between the pairs of investigated biochemical parameters for men data set.

\begin{tabular}{|c|c|c|c|c|c|c|}
\hline Variable & Age & CREA & AST & ALT & GMT & ALP \\
\hline Age & 1.000 & & & & & \\
\hline CREA & 0.170 & 1.000 & & & & \\
\hline AST & -0.081 & -0.128 & 1.000 & & & \\
\hline ALT & -0.287 & -0.090 & 0.889 & 1.000 & & \\
\hline GMT & -0.170 & 0.137 & 0.168 & 0.358 & 1.000 & \\
\hline ALP & 0.290 & -0.042 & -0.039 & -0.048 & 0.021 & 1.000 \\
\hline $\mathrm{CK}$ & 0.021 & 0.048 & 0.110 & 0.039 & 0.036 & -0.298 \\
\hline tCHOL & -0.111 & 0.040 & -0.033 & 0.054 & -0.035 & 0.001 \\
\hline HDLc & 0.171 & -0.128 & 0.094 & 0.135 & 0.022 & -0.130 \\
\hline LDLc & -0.020 & 0.002 & -0.034 & 0.025 & -0.102 & 0.098 \\
\hline TG & -0.352 & 0.181 & -0.073 & 0.006 & 0.122 & -0.143 \\
\hline $\mathrm{AI}$ & -0.281 & 0.156 & -0.092 & -0.053 & -0.072 & 0.129 \\
\hline continuation & CK & tCHOL & HDLc & LDLc & TG & AI \\
\hline $\mathrm{CK}$ & 1.000 & & & & & \\
\hline $\mathrm{tCHOL}$ & -0.084 & 1.000 & & & & \\
\hline HDLc & 0.123 & 0.346 & 1.000 & & & \\
\hline LDLc & -0.094 & 0.927 & 0.240 & 1.000 & & \\
\hline $\mathrm{TG}$ & -0.099 & 0.403 & -0.205 & 0.099 & 1.000 & \\
\hline AI & -0.176 & 0.588 & -0.526 & 0.608 & 0.528 & 1.000 \\
\hline
\end{tabular}

\subsection{Cluster analysis}

Cluster analysis was performed distinctively for the men data set and the women data set. The cluster analysis results are most frequently represented by a dendrogram. Figure 1 depicts the dendrogram, which was calculated using squared Euclidean distance, commonly used in practice. It shows three significant clusters. The first significant cluster is created by tCHOL, LDLc, TG and AI, all representing high cardiovascular risk. The second significant cluster is formed by AST, ALT (characterizing liver enzymes) and third cluster is created by HDLc with CK, CREA with GMT, to which ALP and Age variables are added at larger distance value (Figure 1), which means that these variables are less similar compared to the four ones mentioned. The results for women data set (Figure 2) are similar except the observed clustering of Age, this time with CREA instead of ALP. However, with regard to the most important variables indicating lipidaemia, the situation among men and women is similar. 
Table 2. Summary of correlation coefficients expressing mutual correlation between the pairs of investigated biochemical parameters for women data set.

\begin{tabular}{|c|c|c|c|c|c|c|}
\hline Variable & Age & CREA & AST & ALT & GMT & ALP \\
\hline Age & 1.000 & & & & & \\
\hline CREA & 0.389 & 1.000 & & & & \\
\hline AST & 0.079 & 0.105 & 1.000 & & & \\
\hline ALT & -0.257 & -0.113 & 0.680 & 1.000 & & \\
\hline GMT & -0.103 & 0.163 & 0.188 & 0.279 & 1.000 & \\
\hline ALP & 0.207 & -0.017 & 0.055 & -0.003 & 0.028 & 1.000 \\
\hline $\mathrm{CK}$ & 0.085 & 0.036 & 0.455 & 0.253 & -0.039 & 0.105 \\
\hline $\mathrm{tCHOL}$ & 0.120 & 0.082 & 0.130 & 0.095 & 0.172 & 0.156 \\
\hline HDLc & 0.329 & 0.124 & 0.418 & 0.133 & 0.004 & -0.186 \\
\hline LDLc & 0.037 & -0.016 & -0.031 & -0.003 & 0.100 & 0.164 \\
\hline $\mathrm{TG}$ & -0.090 & 0.065 & -0.210 & 0.040 & 0.253 & 0.341 \\
\hline AI & -0.197 & 0.023 & -0.375 & -0.119 & 0.101 & 0.328 \\
\hline continuation & CK & tCHOL & HDLc & LDLc & TG & AI \\
\hline $\mathrm{CK}$ & 1.000 & & & & & \\
\hline tCHOL & -0.110 & 1.000 & & & & \\
\hline HDLc & 0.007 & 0.368 & 1.000 & & & \\
\hline LDLc & -0.143 & 0.859 & 0.122 & 1.000 & & \\
\hline TG & -0.068 & 0.168 & -0.477 & 0.074 & 1.000 & \\
\hline AI & -0.084 & 0.320 & -0.670 & 0.458 & 0.642 & 1.000 \\
\hline
\end{tabular}

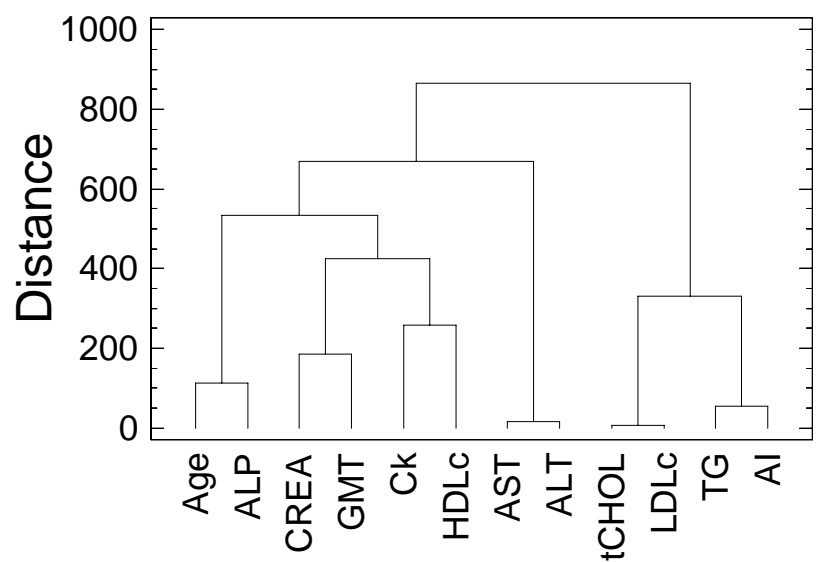

Fig. 1. Dendrogram of cluster analysis of 12 variables for 84 objects (men). Ward's clustering method, Squared Euclidean distance. Software Statgraphics Plus 5.1.

\subsection{Principal component analysis}

The obtained principal component analysis results are visualized in the biplot form (Figure 3). Biplot simultaneously represents the samples together with twelve selected 
variables, depicted by the rays, which start from the origin and end at the point determining the variable position in the plane of principal components.

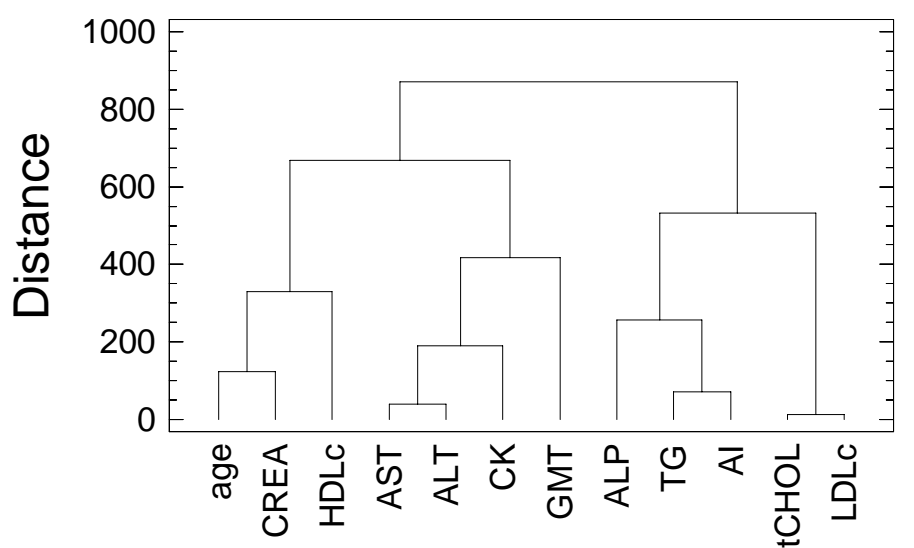

Fig. 2. Dendrogram of cluster analysis of 12 variables for 88 objects (women). Ward's clustering method, Squared Euclidean distance. Software Statgraphics Plus 5.1.

A close position of tCHOL, AI, LDLc and TGT at the shown PCA biplot confirms their mutual dependence found also by correlation analysis and it helps to understanding the $\mathrm{PC} 1$ axis as that expressing the cardiovascular risk. Almost opposite position of HDLc is in correspondence with the previous statement. The variables AST, ALT and GMT as well as their opponents ALP and Age are in the perpendicular position (located along the PC2 axis) to the cholesterol variables, which mean their independence with respect to them. This is also in accordance with the results of correlation analysis.

\subsection{Discriminant analysis}

Discriminant analysis makes a linear combination of the originally selected variables in the way that the discrimination between the classes is mostly pronounced. Table 3 shows a summary of the results of linear discriminant analysis (LDA), quadratic discriminant analysis (QDA) and logistic regression (LR) for the men data set. All these methods are used for classification of the patient samples into two classes - before (class 1) and after (class 2) treatment by statins. The results for training set (used for calculating the classification model) and leave-one-out method validation (one object is left out from the training set in a stepwise mode until all objects are interchanged) are represented in per cents. Success in validation step, where the samples independent of the calculations performed in the training process, is more important for overall assessment of the classification method. It is obvious that the predictive ability is better for LDA than the QDA. However, the most promising are the results achieved by logistic regression. 


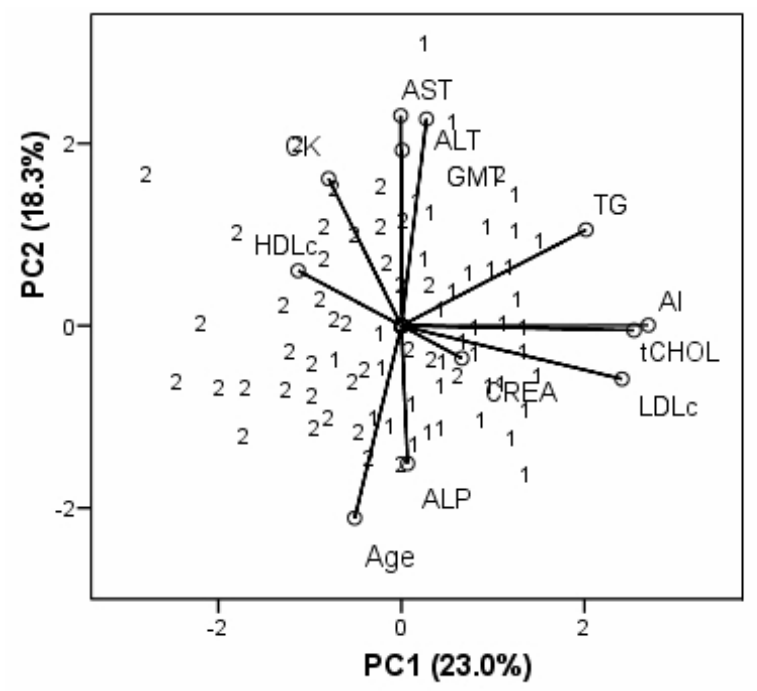

Fig. 3. Biplot PC1 vs. PC2 (men), 12 variables (with the symbols specified in part 2), 84 patient samples. Software Statgraphics Plus 5.1.

Table 3. Results of discriminant analysis (LDA, QDA) and LR for two software packages (SPSS, SAS) classification of the men samples into two categories: before and after statin treatment.

\begin{tabular}{cccccc}
\hline \multirow{2}{*}{ Method } & \multirow{2}{*}{ Results } & \multicolumn{2}{c}{ SPSS } & \multicolumn{2}{c}{ SAS } \\
\cline { 3 - 6 } & & Training set & Leave-one-out & Training set & Leave-one-out \\
\hline \multirow{2}{*}{ LDA } & true/all & $73 / 84$ & $67 / 84$ & $73 / 84$ & $67 / 84$ \\
& $\%$ true & 86.9 & $\mathbf{7 9 . 8}$ & 86.9 & $\mathbf{7 9 . 8}$ \\
\hline \multirow{2}{*}{ QDA } & true/all & $73 / 84$ & n.a. & $70 / 84$ & $55 / 84$ \\
& $\%$ true & 86.9 & n.a. & 83.3 & $\mathbf{6 5 . 5}$ \\
\hline \multirow{2}{*}{ LR } & true/all & $75 / 84$ & n.a. & $75 / 84$ & $72 / 84$ \\
& $\%$ true & 89.3 & n.a. & 89.3 & $\mathbf{8 5 . 7}$ \\
\hline
\end{tabular}

n.a. - not accessed.

Tabable 4.: Results of discriminant analysis (LDA, QDA) and LR for two software packages (SPSS, SAS) classification of the women samples into two categories: before and after statin treatment.

\begin{tabular}{cccccc}
\hline \multirow{2}{*}{ Method } & \multirow{2}{*}{ Results } & \multicolumn{2}{c}{ SPSS } & \multicolumn{2}{c}{ SAS } \\
\cline { 3 - 6 } & & Training set & Leave-one-out & Training set & Leave-one-out \\
\hline \multirow{2}{*}{ LDA } & true/all & $81 / 88$ & $74 / 88$ & $81 / 88$ & $74 / 88$ \\
& $\%$ true & 92.0 & $\mathbf{8 4 . 1}$ & 92.0 & $\mathbf{8 4 . 1}$ \\
\hline \multirow{2}{*}{ QDA } & true/all & $81 / 88$ & n.a. & $76 / 88$ & $61 / 88$ \\
& $\%$ true & 92.0 & n.a. & 86.4 & $\mathbf{6 9 . 3}$ \\
\hline \multirow{2}{*}{ LR } & true/all & $79 / 88$ & n.a. & $79 / 88$ & $77 / 88$ \\
& $\%$ true & 89.8 & n.a. & 89.8 & $\mathbf{8 7 . 5}$ \\
\hline
\end{tabular}

n.a. - not accessed 


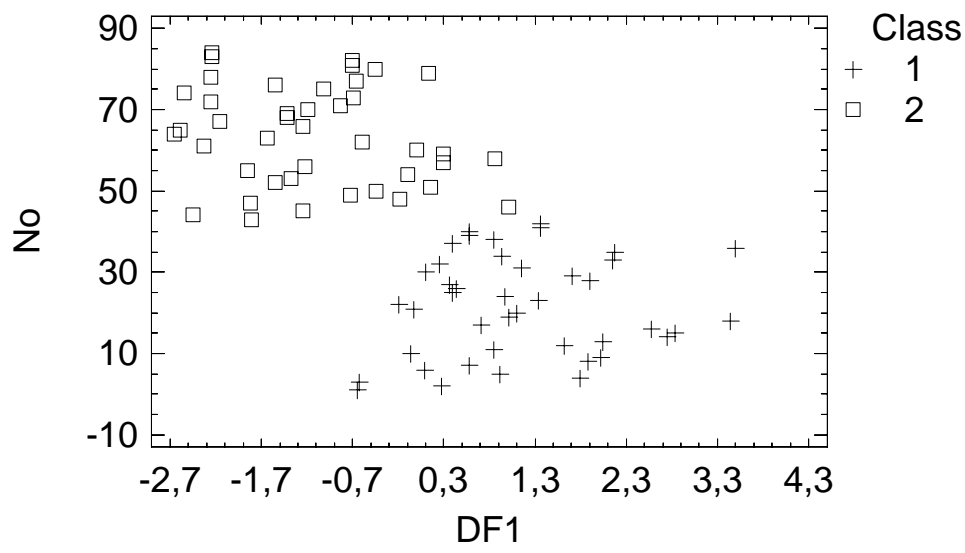

Fig. 4. LDA Scatterplot of 84 patient samples (men) marked by number (No) calculated from 12 variables. DF1 is the only discriminant function. Class 1 - before, class 2 - after treatment by statins. Software Statgraphics Plus 5.1.

A good separation between the investigated two categories of the patient samples is confirmed also in Figure 4, calculated also for the men data set. The results for women data set are collected in Table 4. All results referring to the training set are close to or over $90 \%$ of the correct results, the best outcome in validation by leave-one-out method was obtained for LR.

\section{Conclusions}

Treatment of patients with the risk of a developing coronary artery disease can be successfully monitored using the visualization and classification methods of multidimensional statistical analysis. The interrelation of eleven biochemical laboratory parameters as well as the patient's age and gender was investigated in detail. Achieved results enable to evaluate the treatment by statins in each individual case. They may also help in estimation of the pertaining cardiovascular risk after the statin drug administration and in monitoring the dynamic progression of the disease.

Acknowledgement: The support of this work by the grants VEGA 1/1005/09 and VVCE-000407 is acknowledged.

\section{References}

FUJITA, M., YAMAZAKIB, T., HAYASHIC, D., KOHROC, T., OKADAC, Y., NAGAI, R.: Pleiotropic effects on cardiovascular events in the Japanese Coronary Artery Disease study. Int. J. Cardiol., 129, 2008, 294-296.

GARCIA, I., MUNTEANU, C.R., FALL, Y., GÓMEZ, G., URIARTE, E., GONZÁLEZ-DÍAZ, H.: QSAR and complex network study of the chiral HMGR inhibitor structural diversity. Bioorg. Med. Chem., 17, 2009, 165-175. 
GOUNARI, P., TOUSOULIS, D., ANTONIADES, C., KAMPOLI, A.M., STOUGIANNOS, P., PAPAGEORGIOU, N., ROULIA, G., STEFANADI, E., SIASOS, G., TSIOUFIS, C., STEFANADIS, C.: Rosuvastatin but not ezetimibe improves endothelial function in patients with heart failure, by mechanisms independent of lipid lowering. Int. J. Cardiol., 2009, (in press) .

GROMANOVÁ, G.: Influence of Hypolipidaemic treatment by statins on levels of selected biochemical parameters (in Slovak). Diploma Thesis, TU Trnava, 2008.

ISTVAN, E., DEISENHOFER, J.: Statin inhibition of HMG-CoA reductase: a 3dimensional view. Atherosclerosis Suppl., 4, 2003, 3-8.

KASTELEIN, J.J.P.: The future of best practise. Atherosclerosis 143, 1999, S17-S21.

LIAO, J.K.: Beyond lipid lowering: the role of statins in vascular protection. Int. J. Cardiol., 86, 2002, 5-18.

MASSART, D.L., VANDEGINSTE, B., BUYDENS, L., De JONG, S., LEWI, P., SMEYERS-VERBEKE, J.: Handbook of Chemometrics and Qualimetrics, Part A, Elsevier, Amsterdam, 1997, $886 \mathrm{pp}$.

MELOUN, M., MILITKÝ J.: Compendium of Statistical Data Processing (in Czech), Academia, Praha, 2002, 764 pp.

OTTO, M.: Chemometrics: Statistics and Computer Application in Analytical Chemistry, Wiley, Weinheim, 1999, $314 \mathrm{pp}$.

SHARMA, S.: Applied multivariate techniques, J. Wiley, New York, 1996, 588 pp.

SHIMOKATA, K., YAMADAC, Y., KONDO, T., ICHIHARA, S., IZAWA, H., NAGATA, K., MUROHARA, T., OHNOD, M., YOKOTA, M.: Association of gene polymorphisms with coronary artery disease in individuals with or without nonfamilial hypercholesterolemia. Atherosclerosis, 172, 2004, 167-173.

VANDEGINSTE, B., MASSART, D.L., BUYDENS, L., De JONG, S., LEWI P., SMEYERS-VERBEKE, J.: Handbook of Chemometrics and Qualimetrics, Part A, Amsterdam, Elsevier, 1997, 876 pp. 